\title{
Congenital Heart Disesase: A Retrospective Analysis from a Tertiary Referral Centre in Portugal
}

\author{
Diogo Faim, ${ }^{\circledR}$ Joaquim Tiago, ${ }^{2}{ }^{\circledR}$ Rui Castelo, ${ }^{2 \oplus}$ Andreia Francisco, ${ }^{1}{ }^{\circledR}$ Rosa Alves, ${ }^{2}{ }^{\circledR}$ António Pires ${ }^{1}$ \\ Hospital Pediátrico de Coimbra, Centro Hospitalar e Universitário de Coimbra, Paediatric Cardiology Department, 'Coimbra - Portugal \\ Maternidade Dr. Daniel de Matos, Centro Hospitalar e Universitário de Coimbra, Neonatology and Neonatal Intensive Care Department, ${ }^{2}$ Coimbra - Portugal
}

\section{Abstract}

Background: Congenital heart disease is the leading cause of mortality among all congenital malformations.

Objectives: To evaluate the incidence of congenital heart diseases in a central maternity hospital in Portugal from January 2003 to December 2018 and to determine survival in the first year of life.

Methods: Retrospective analysis of newborns diagnosed with congenital heart diseases within 72 hours after birth. Malformations were divided according to pathophysiology. Cumulative survival analysis was performed by the Kaplan-Meier test. Stastical significance was set at $\mathrm{p}<0.05$.

Results: A total of 297 newborns with cardiac malformation was recorded among 47,198 live births (incidence of 6:1000), 16\% associated with extra-cardiac disease. The most frequent congenital heart diseases were left-toright shunt lesions $(n=216)$, followed by cyanotic $(n=41)$, acyanotic obstructive $(n=31)$ and miscellaneous $(n=$ 9). Seventy ( $24 \%$ ) patients had prenatal diagnosis, $88 \%$ of them cyanotic defects, and a positive association was found between prenatal diagnosis and mortality $(\mathrm{p}<0.001)$. Coarctation of the aorta was associated with gestational diabetes $(p=0.014)$. Atrial septal defect was more common in females $(p=0.02)$. Mortality rate due to heart disease was 3.4\%. Patients with cyanotic disease, 99\%, 97\%, 97\%, respectively, for patients with left-to-right shunt lesions, and $97 \%, 97 \%, 97 \%$ for those with obstructive lesion cases.

Conclusion: The incidence of congenital heart disease was 6:1000, mostly left-to-right shunt lesions. Heart disease accounted for only half of deaths, and cyanotic diseases have a high nonspecific mortality rate.

Keywords: Congenital Heart Defect; Newborn Infant; Neonatology; Survival.

\section{Introduction}

Congenital heart diseases (CHDs) are a group of malformations that are the leading cause of perinatal mortality. ${ }^{1}$ Their prevalence is estimated to be six to 10 per 1,000 births. $^{1-4}$

Due to advances in diagnostic techniques, the prevalence of CHDs has increased over the years. $3,5,6$ Therapeutic innovations, both medical and surgical, have contributed to reduction in mortality, ${ }^{7}$ and most patients with CHD reach adulthood today. ${ }^{5,6}$ However, these patients are at a higher risk of developing comorbidities, ${ }^{8}$ including higher levels of psychological stress. ${ }^{7}$
CHD was defined by Mitchel ${ }^{9}$ in 1971 as a structural anomaly of the heart or large vessels that is could be of functional significance. Although the etiology of CHD is largely unknown, the risk factors known to be related to CHD include maternal infections (e.g., rubella) or conditions (gestational diabetes and obesity, use of vitamin A) and use of teratogenic drugs, tobacco, alcohol and cocaine during pregnancy. ${ }^{1,4}$ Medically assisted reproduction ${ }^{10}$ and being a child of a mother with heart disease are also associated with CHD. ${ }^{11}$ Heart diseases that pose the greatest risk for the development of CHD in the offspring are aortic stenosis, atrioventricular septal

Mailing Address: Diogo Faim

Praceta, R. Prof. Mota Pinto, 3075. Postal Code: 3000-075, Coimbra - Portugal.

E-mail: diogofaim92@gmail.com 
defect and tetralogy of Fallot. Other diseases may pose a lower risk, such as atrial and ventricular septal defects, coarctation of the aorta, patente ductos arteriosus and pulmonar stenosis. ${ }^{12}$

The aim of this study was to characterize the incidence of CHD in a central maternity hospital and, to assess survival at 28 days, six months and one year of life, in different CHD groups.

\section{Methods}

\section{Population}

Retrospective study of newborns with CHD, born in a central maternity hospital in Portugal between 01 January 2003 and 31 December 2018.

\section{Congenital heart disease}

The diagnosis was made by transthoracic echocardiography by a pediatric cardiologist within 72 hours of life. Congenital heart diseases were classified according to the International Pediatric and Congenital Cardiac Code. ${ }^{13}$ All cases of prenatal diagnosis of CHD were confirmed in the postnatal period.

All cases of patent ductus arteriosus were included in this study if present 72 hours of life in term newborns. Cases described as patent foramen ovale and restrictive ostium secundum atrial septal defects were excluded.

In patients with complex cardiac defects, the main (predominant) cardiac defect was chosen as the primary diagnosis. The conditions were divided into three categories, "cyanotic", "obstructive" and "leftto-right shunting" according to the pathophysiological mechanism. ${ }^{14}$ Diseases that did not fit into any of the three categories were classified in a fourth category, "miscellaneous".

This study was approved by the ethics and research committe of our hospital.

\section{Statistical analysis}

The SPSS $®$ program (IBM $®$, SPSS $®$ Statistics Inc., Chicago), version 25.0 was used for statistical analysis. Normality of data was tested by the Shapiro-Wilk test. Continuous variables with normal distribution were described as mean and standard deviation (SD) and continuous variables without normal distribution were described as median and interquartile range (IQR). The Fisher's exact test and chi-square test were used to verify associations between categorical variables. Survival curves were based on the Kaplan Meier test. The significance level was set as $5 \%$.

\section{Results}

Of a total of 47,198 neonates born during the study period, 297 had CHD, 83 of them complex heart disease $(28 \%)$. As shown in the Table 1, most of cardiac malformations were left-to-right shunt lesions (73\%), followed by cyanotic (14\%), acyanotic obstructive (10\%) and miscellaneous (3\%) lesions. The incidence of CHD was about six per 1,000 births.

Mean maternal age was 32 years (SD \pm 5$)$, and median number of both pregnancies and deliveries was one (IQR 1:2).

In 12 women, pregnancies were complicated by gestational diabetes. The only CHD associated with gestational diabetes was coarctation of the aorta ( $p$ $=0.014)$. There were 17 cases of prenatal maternal infections, none related to CHD. Previous familial CHD was present in two cases: a newborn with tetralogy of Fallot, whose mother had the same condition, and another with partial anomalous pulmonary venous return and atrial septal defect, whose father had transposition of the great arteries.

Of all the CHD cases, 70 (24\%) patients had prenatal diagnosis $-88 \%$ of patients with cyanotic lesions, $32 \%$ of patietns with obstructive lesions, $11 \%$ of those with miscellaneous, and $11 \%$ of patients with left-to-right shunting. A positive association was found between prenatal diagnosis and mortality $(\mathrm{p}<0.001)$.

Mean gestational age was 38 weeks (IQR 35: 39), 22\% of newborns were preterm. The median Apgar score at the fifth minute of life was 10 (IQR 9: 10) and median birth weight was 3,110 grams (IQR 2570: 3505).

Of the 297 newborns with CHD, 149 were male and 47 cases (16\%) were associated with extra-cardiac anomalies/ malformations. The associations between CHD and gender and CHD and extra-cardiac malformations are summarized in Tables 2 and 3, respectively.

About $25 \%$ of patients needed pharmacological therapy in the neonatal period. Cardiac catheterization was performed in 35 patients, with Rashkind atrioseptostomy in 13 of them. Sixty-one patients $(20 \%)$ underwent surgery. Most of patients who underwent surgery had 
Table 1 - Prenatal diagnosis and mortality rate of infants with congenital heart disease $(n=297)$

\begin{tabular}{|c|c|c|c|c|}
\hline Congenital Heart Disease & $\mathbf{N}$ & $\%$ & PND (n) & Mortality (n) \\
\hline Cyanotic defects & 41 & 14 & 36 & 8 \\
\hline Transposition of the great arteries & 16 & 5.4 & 15 & 5 \\
\hline Tetralogy of Fallot & 15 & 5.2 & 14 & 0 \\
\hline Hypoplastic left heart syndrome & 3 & 1.1 & 2 & 2 \\
\hline Double outlet right ventricle & 3 & 1.1 & 2 & 0 \\
\hline Ebstein's anomaly & 1 & 0.3 & 1 & 1 \\
\hline Pulmonary atresia with ventricular septal defect & 1 & 0.3 & 1 & 0 \\
\hline Total anomalous pulmonary venous connection & 1 & 0.3 & 0 & 0 \\
\hline Truncus arteriosus & 1 & 0.3 & 1 & 0 \\
\hline Acyanotic obstructive & 31 & 10 & 10 & 1 \\
\hline Coarctation of the aorta & 14 & 4.6 & 4 & 0 \\
\hline Valvular aortic stenosis & 8 & 2.5 & 5 & 1 \\
\hline Valvular pulmonary stenosis & 6 & 2 & 0 & 0 \\
\hline Shone's syndrome & 2 & 0.6 & 1 & 0 \\
\hline Left branch pulmonary artery stenosis & 1 & 0.3 & 0 & 0 \\
\hline Left-to-right shunt lesion & 216 & 73 & 23 & 7 \\
\hline Ventricular septal defect & 144 & 48.6 & 15 & 2 \\
\hline Atrial septal defect & 42 & 14.1 & 3 & 4 \\
\hline Patent ductus arteriosus & 24 & 8.2 & - & 0 \\
\hline Complete atrioventricular canal defect & 5 & 1.8 & 4 & 1 \\
\hline Partial anomalous pulmonary venous connection & 1 & 0.3 & 1 & 0 \\
\hline Miscellaneous & 9 & 3 & 1 & 0 \\
\hline Isolated bicuspid aortic valve & 4 & 1.4 & 0 & 0 \\
\hline Left ventricular noncompactation & 2 & 0.6 & 1 & 0 \\
\hline Major aortopulmonary collateral arteries & 2 & 0.6 & 0 & 0 \\
\hline Criss-cross heart & 1 & 0.3 & 0 & 0 \\
\hline
\end{tabular}

cyanotic CHD (77\%), followed by obstructive (48\%) and left-to- right shunt lesions (7\%).

Mortality rate from heart disease was 3.4\% $(n=10$; eight cyanotic lesions, one acyanotic obstructive and one left-to-right shunt lesion). The patient with acyanotic obstructive lesion had critical aortic stenosis. Although most deaths occurred in patients with left-to-right shunt lesion, only one death was due to the heart disease, an eight-month-old infant with complete atrioventricular septal defect. Overall mortality rate in the first year of life was $5.4 \%(n=16)$, half of deaths occurred in the neonatal period. The median age of death was 25 days (IQR 5: 225). Of the 16 patients who died, 30\% had extracardiac disease. Mortality by group and type of CHD is described in Table 1. Overall survival curves at 28 days, six months and one year of life are shown in Figures 1, 2 and 3 , respectively. 
Table 2 - Associations between congenital heart disease and gender

\begin{tabular}{|c|c|c|c|}
\hline Congenital heart disease & Male (n) & Female (n) & $\mathrm{p}$ - value \\
\hline Transposition of the great arteries & 7 & 9 & 0.598 \\
\hline Tetralogy of Fallot & 11 & 4 & 0.066 \\
\hline Hypoplastic left heart syndrome & 1 & 2 & 0.622 \\
\hline Double outlet right ventricle & 3 & 0 & 0.247 \\
\hline Ebstein's anomaly & 0 & 1 & 1 \\
\hline Pulmonary atresia with ventricular septal defect & 1 & 0 & 1 \\
\hline Total anomalous pulmonary venous connection & 1 & 0 & 1 \\
\hline Truncus arteriosus & 1 & 0 & 1 \\
\hline Coarctation of the aorta & 7 & 7 & 0.99 \\
\hline Valvular aortic stenosis & 3 & 5 & 0.501 \\
\hline Valvular pulmonary stenosis & 1 & 5 & 0.121 \\
\hline Shone's syndrome & 0 & 2 & 0.247 \\
\hline Left branch pulmonary artery stenosis & 1 & 0 & 1 \\
\hline Ventricular septal defect & 76 & 68 & 0.384 \\
\hline Atrial septal defect & 14 & 28 & 0.019 \\
\hline Complete atrioventricular canal defect & 2 & 3 & 0.371 \\
\hline Patent ductus arteriosus & 10 & 14 & 0.385 \\
\hline Partial anomalous pulmonary venous connection & 0 & 1 & 1 \\
\hline Isolated bicuspid aortic valve & 4 & 0 & 0.122 \\
\hline Left ventricular noncompactation & 2 & 0 & 0.498 \\
\hline Major aortopulmonary collateral arteries & 2 & 0 & 0.498 \\
\hline Criss-cross heart & 1 & 0 & 1 \\
\hline
\end{tabular}

\section{Discussion}

The authors of this study set out to describe CHDs in neonates born in a central maternity hospital. First, it is important to higlight the differences between disease prevalence and incidence. Several CHD studies have presented prevalence data over time, due to the fact that many CHDs are only diagnosed during the first year of life, while others heal spontaneously during the same period of time. ${ }^{7}$ In this context, some authors have opted to report the number of new cases of CHD at birth, namely the incidence of these diseases. In our study, the incidence of CHD was about six cases per 1,000 births, similar to that described in the literature., ${ }^{1,15-18}$ Some studies, ${ }^{5,6,19}$ however, have estimated an incidence of eight to 10 per 1,000 births. A possible explanation for this difference is the subjectivity in diagnostic criteria for patent foramen ovale and atrial septal defect. The former was excluded from the present study because it is not a CHD, as were patent ductos arteriosus in preterm neonates and neonatal arrhythmias. ${ }^{1,3,9}$

Several studies ${ }^{3,5,6,16}$ have shown that both the incidence and prevalence of CHDs have been increasing, which is possibly related to improvements in diagnostic techniques, and advances in health care and CHD management. However, some authors have argued that CHD prevalence has stabilized ${ }^{4}$ or even decreased, ${ }^{17}$ due to the increase in prenatal diagnosis, and, implicitly, in the number of pregnancy terminations.

Although some authors advocate a classification of CHD based on clinical severity, , $^{1820,21}$ in our study, CHDs were classified based on their pathophysiological 
Table 3 - Associations between congenital heart disease and extra-cardiac malformations

\begin{tabular}{|c|c|c|c|}
\hline Congenital heart disease & $\begin{array}{l}\text { With extra cardiac } \\
\text { malformation }\end{array}$ & $\begin{array}{c}\text { Without } \\
\text { extra cardiac } \\
\text { malformation }\end{array}$ & $\mathrm{p}$ - value \\
\hline Transposition of the great arteries & 3 & 13 & 0.725 \\
\hline Tetralogy of Fallot & 3 & 12 & 0.714 \\
\hline Hypoplastic left heart syndrome & 0 & 2 & 1 \\
\hline Double outlet right ventricle & 0 & 3 & 1 \\
\hline Ebstein's anomaly & 0 & 1 & 1 \\
\hline Pulmonary atresia with ventricular septal defect & 0 & 1 & 1 \\
\hline Total anomalous pulmonary venous connection & 0 & 1 & 1 \\
\hline Truncus arteriosus & 0 & 1 & 1 \\
\hline Coarctation of the aorta & 5 & 9 & 0.053 \\
\hline Valvular aortic stenosis & 2 & 6 & 0.617 \\
\hline Pulmonary valve stenosis & 2 & 4 & 0.242 \\
\hline Shone's syndrome & 0 & 2 & 1 \\
\hline Left branch pulmonary artery stenosis & 0 & 1 & 1 \\
\hline Ventricular septal defect & 15 & 129 & 0.013 \\
\hline Atrial septal defect & 11 & 31 & 0.047 \\
\hline Complete atrioventricular canal defect & 4 & 1 & 0.002 \\
\hline Patent ductus arteriosus & 0 & 24 & 0.019 \\
\hline Partial anomalous pulmonary venous connection & 0 & 1 & 1 \\
\hline Isolated bicuspid aortic valve & 0 & 4 & 1 \\
\hline Left ventricular noncompactation & 2 & 0 & 0.025 \\
\hline Major aortopulmonary collateral arteries & 0 & 2 & 1 \\
\hline Criss-cross heart & 0 & 1 & 1 \\
\hline
\end{tabular}

mechanism, which allows grouping of diseases with relatively similar mechanisms of action but highlighting their prognostic differences.

CHDs have been linked to several risk factors, including maternal risk factors during pregnancy. ${ }^{1,4}$ The most important ones are infections and gestational diabetes. Samánek ${ }^{7}$ observed that the highest peak incidence of CHD occurred eight to nine months after a influenza virus epidemic. Øyen et al. ${ }^{22}$ reported that the incidence of CHD, regardless of phenotype, is four times higher in children of women who developed gestational diabetes during pregnancy. In this study, coarctation of the aorta was the only lesion related with gestational diabetes. Another risk factor reported is the increased incidence of
CHD in children from parents with $\mathrm{CHD},{ }^{11,23}$ and genetic predisposition. ${ }^{24}$ In our study, we found a newborn with tetralogy of Fallot, born to a woman with the same disease, and another newborn with partial anomalous pulmonary venous return and atrial septal defect, whose father had transposition of the great arteries.

The presence of prenatal diagnosis was significantly related to mortality. Most patients $(88 \%)$ with prenatal diagnosis had cyanotic lesions, which carry a worse prognosis. Of the 41 patients with cyanotic CHD, only five had no prenatal diagnosis.

Atrial septal defect occurred more often in females and was the only condition that showed statistically significant gender preference $(p=0.02)$. These results, 


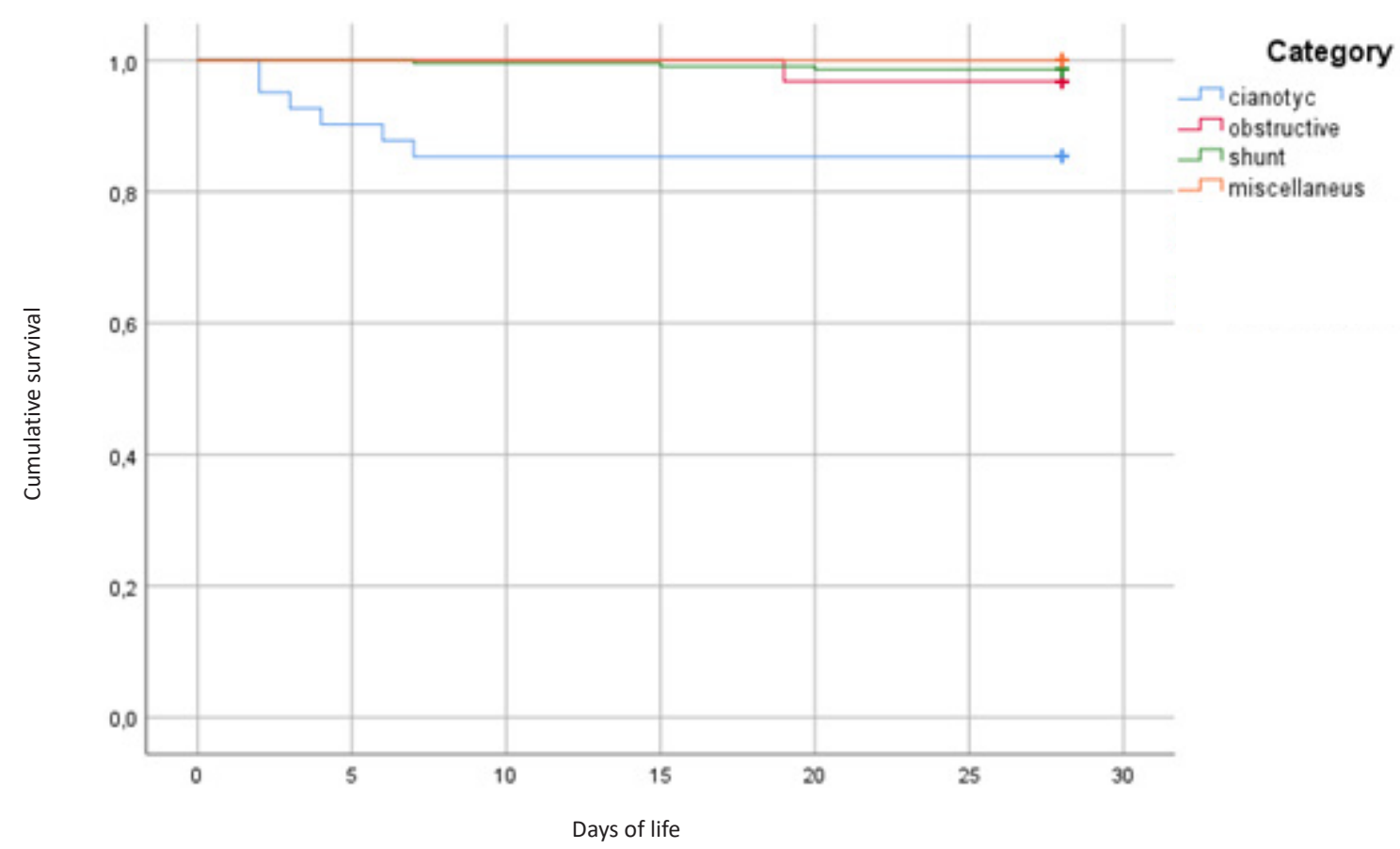

Figure 1 - Overall survival at 28 th day of life $(97 \%)$ by disease category - cyanotic $85 \%$, obstructive acyanotic $97 \%$, left to right shunt lesions $99 \%$, miscellaneus $100 \%$.

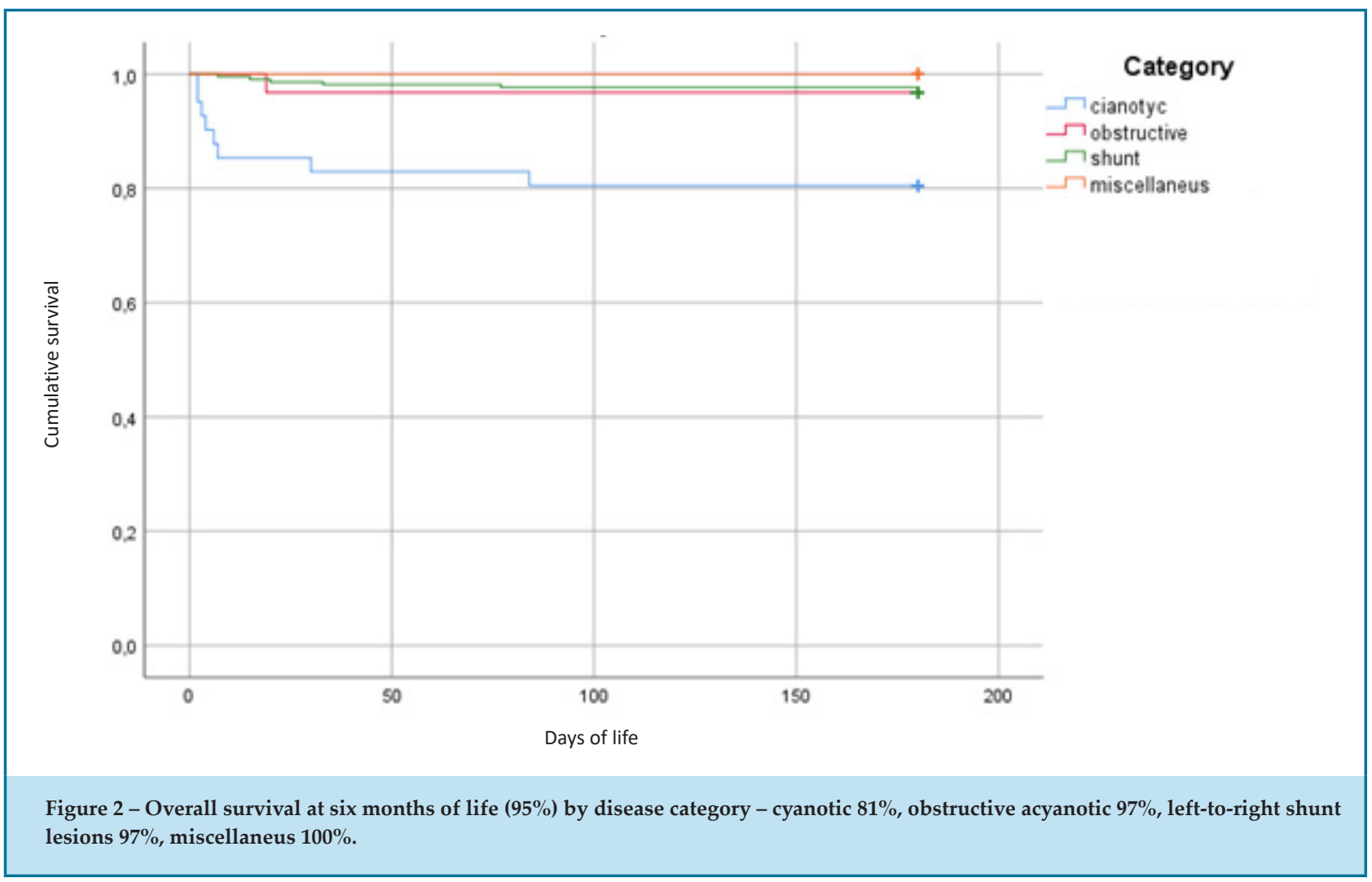




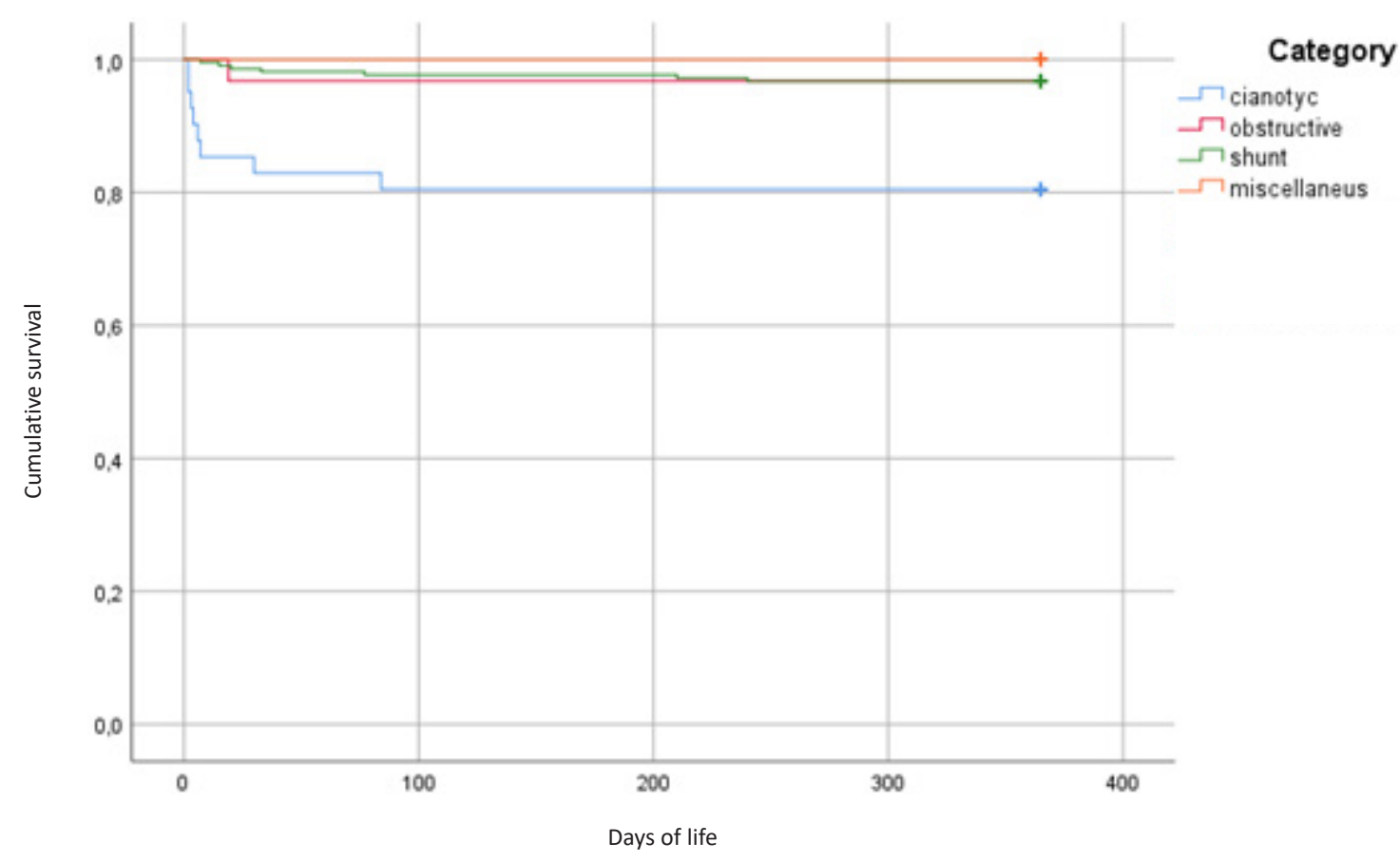

Figure 3 - Overall survival at the first year of life ( $95 \%$ ) by disease category - cyanotic $81 \%$, obstructive acyanotic $97 \%$, left-to-right shunt lesions $97 \%$, miscellaneus $100 \%$.

and those for pulmonary valve stenosis reflect the trends published in the literature. ${ }^{2}$ As in the study by Mercuro et al., ${ }^{25}$ double outlet right ventricle, tetralogy of Fallot and bicuspid aortic valve were also more frequently found in male than in female neonates.

Overall mortality rate in the first year of life was $5.4 \%$, similar to the results obtained by Khoshnood et al., ${ }^{19}$ who also showed that mortality was highest in the neonatal period. Dolk et al., ${ }^{1}$ reported a perinatal mortality in patients with congenital anomalies of 0.93 per 1,000 births, with $26 \%$ of these deaths in patients with CHD. Thus, CHDs are the main group of diseases contributing to perinatal mortality. It should be noted, however, that these patients have a higher incidence of other comorbidities. In our analysis, mortality related to CHD was $3.4 \%(n=10)$, and none of these deaths occurred in the miscellaneous group in the first year of life. In the remaining deaths, the main causes were extreme prematurity, sepsis, intraventricular hemorrahage and Patau and Edwards syndromes. Samánek ${ }^{7}$ reported that of all deaths in patients with congenital heart disease, only $48 \%$ were related to CHD. Massin et al., ${ }^{26}$ observed noncardiac comorbidities in 15 to $45 \%$ of autopsies in patients with CHD. Other authors have documented the association of CHD with diaphragmatic hernia, esophageal atresia, omphalocele ${ }^{27}$ and poor neurological outcomes. ${ }^{2}$ We observed that $32 \%$ of patients with extra-cardiac disease or syndromes had ventricular septal defects $(p=0.013)$. Complete atrioventricular canal defect, atrial septal defect and left ventricular noncompactation were positively associated with extra-cardiac malformations, such as craniofacial malformations, renal agenesis/hypoplasia, diaphragmatic hernia, cleft lip and cleft palate, esophageal atresia and polymalformative syndromes. Patent ductus arteriosus had a negative association with those.

Survival curves were built to assess overall mortality at 28 days, six months and one year of life according to disease category. Cyanotic diseases have shown the highest mortality in all life periods. As observed in our study, and concordant with others, cyanotic CHDs carry the worst prognosis, whose morbidity and mortality go beyond the neonatal period. Unlike our results, in a study ${ }^{7}$ by Samánek published in 2000, the one- year mortality was higher, which probably reflects improvements in health care. More recently, Oster et al., ${ }^{21}$ reported a survival rate of $75 \%$ for critical CHDs and $97 \%$ for non-critical CHDs at one year of age. 
Advances in therapeutic modalities have led to decreasing mortality rates. Marelli et al., ${ }^{6}$ showed that mortality decreased by 40\% between 1979 and 1993, and that the prevalence of CHD increased by more than half between 2000 and 2010, mainly due to the surviving adult population. With this increased in survival, CHD is no longer just a pediatric problem, but one that seeps into adulthood. Bracher et al., ${ }^{8}$ reported that the most common comorbidities in adults with congenital heart disease are hypertension, thyroid dysfunction, psychiatric disorders, neurological disorders, chronic lung disease and stroke. Smith et al., ${ }^{28}$ showed that newborns with cyanotic CHDs are at a higher risk for silent ischemic cerebral stroke in the adulthood and that arrhythmias are the leading cause of death in this age group.

As far as we know, our study is the first epidemiological study to infants with CHDs born in a central maternity hospital in the main territory of Portugal. In 2006, Cymbron et al. ${ }^{15}$ conducted an identical study on an island in the Azores, Portugal, and found an incidence of 9.16 per 1,000 live births. These results may be due to the existence of several family clusters in a relatively small area.

This study has the inherent limitations of being a retrospective analysis.

\section{Conclusion}

The incidence of CHD in our study group was approximately six per 1,000 births, and left-to-right shunt lesions were the most prevalent. Heart disease accounted for $62 \%$ of total deaths. Cyanotic CHDs had

\section{References}

1. Dolk H, Loane M, Garne E. The prevalence of congenital anomalies in Europe. Adv Exp Med Biol. 2010;686:349-64. doi: 10.1007/978-90-4819485-8_20.

2. Sampayo F, Pinto FF. Distribuição por sexos das cardiopatias congénitas. Acta Med Port. 1994;7(7-8):413-8.

3. Hoffman JI, Kaplan S. The incidence of congenital heart disease. J Am Coll Cardiol. 2002;39(12):1890-900. doi: 10.1016/s0735-1097(02)01886-7.

4. van der Linde D, Konings EE, Slager MA, Witsenburg M, Helbing WA, Takkenberg JJ, et al. Birth prevalence of congenital heart disease worldwide: a systematic review and meta-analysis. J Am Coll Cardiol. 2011;58(21):2241-7. doi: 10.1016/j.jacc.2011.08.025.

5. Gilboa SM, Devine OJ, Kucik JE, Oster ME, Riehle-Colarusso T, Nembhard WN, et al. Congenital heart defects in the United States: estimating the magnitude of the affected population in 2010. Circulation. 2016;134(2):101-9. doi: 10.1161/CIRCULATIONAHA.115.019307.

6. Marelli AJ, Ionescu-Ittu R, Mackie AS, Guo L, Dendukuri N, Kaouache M. Lifetime prevalence of congenital heart disease in the general the highest prenatal diagnosis rate and were associated with increasing mortality rates over the first year of life. There has been an increase in the prevalence of CHD and its survival over time, leading to a shift in paradigm in health care towards comorbidities associated with CHD in adolescence and adulthood.

\section{Potential Conflict of Interest}

No potential conflict of interest relevant to this article was reported.

\section{Sources of Funding}

There were no external funding sources for this study.

\section{Study Association}

This study is not associated with any thesis or dissertation work.

\section{Ethics approval and consent to participate}

This article does not contain any studies with human participants or animals performed by any of the authors.

\section{Author contributions}

Conception and design of the research: Faim D, Tiago J, Castelo R, Francisco A. Acquisition of data: Faim D, Tiago J, Alves R. Analysis and interpretation of the data: Faim D. Statistical analysis: Faim D. Writing of the manuscript: Faim D. Critical revision of the manuscript for intellectual content: Tiago J, Castelo R, Francisco A, Alves R, Pires A. population from 2000 to 2010. Circulation. 2014;130(9):749-56. doi: 10.1161/CIRCULATIONAHA.113.008396.

7. Samánek M. Congenital heart malformations: prevalence, severity, survival, and quality of life. Cardiol Young. 2000;10(3):179-85. doi: 10.1017/s1047951100009082.

8. Bracher I, Padrutt M, Bonassin F, Lopes BS, Gruner C, Stämpfli SF, et al. Burden and impact of congenital syndromes and comorbidities among adults with congenital heart disease. Int J Cardiol. 2017;240:159-64. doi: 10.1016/j.ijcard.2017.02.118.

9. Mitchell SC, Korones SB, Berendes HW. Congenital heart disease in 56,109 births. Incidence and natural history. Circulation. 1971;43(3):323-32. doi: 10.1161/01.cir.43.3.323.

10. Giorgione V, Parazzini F, Fesslova V, Cipriani S, Candiani M, Inversetti A, et al. Congenital heart defects in IVF/ICSI pregnancy: systematic review and meta-analysis. Ultrasound Obstet Gynecol. 2018;51(1):33-42. doi: 10.1002/uog.18932. 
11. Yokouchi-Konishi T, Yoshimatsu J, Sawada M, Shionoiri T, Nakanishi A, Horiuchi $\mathrm{C}$, et al. Recurrent Congenital heart diseases among neonates born to mothers with congenital heart diseases. Pediatr Cardiol. 2019;40(4):865-70. doi: 10.1007/s00246-019-02083-6.

12. Nora JJ, Nora AH. Maternal transmission of congenital heart diseases: new recurrence risk figures and the questions of cytoplasmic inheritance and vulnerability to teratogens. Am J Cardiol. 1987;59(5):459-63. doi: 10.1016/0002-9149(87)90956-8.

13. Franklin RC, Jacobs JP, Krogmann ON, Béland MJ, Aiello VD, Colan $\mathrm{SD}$, et al. Nomenclature for congenital and paediatric cardiac disease: historical perspectives and The International Pediatric and Congenital Cardiac Code. Cardiol Young. 2008;18(Suppl 2):70-80. doi: 10.1017/ S1047951108002795.

14. Park MK. Park's The Pediatric Cardiology Handbook. 5th ed. Baltimore: Mosby; 2007.

15. Cymbron T, Anjos R, Cabral R, Macedo C, Duarte CP, Mota-Vieira L. Epidemiological characterization of congenital heart disease in São Miguel Island, Azores, Portugal. Community Genet. 2006;9(2):107-12. doi: $10.1159 / 000091488$

16. Botto LD, Correa A, Erickson JD. Racial and temporal variations in the prevalence of heart defects. Pediatrics. 2001;107(3):E32. doi: 10.1542/ peds.107.3.e32

17. Egbe A, Uppu S, Lee S, Ho D, Srivastava S. Changing prevalence of severe congenital heart disease: a population-based study. Pediatr Cardiol. 2014;35(7):1232-8. doi: 10.1007/s00246-014-0921-7.

18. Mat Bah MN, Sapian MH, Jamil MT, Abdullah N, Alias EY, Zahari N. The birth prevalence, severity, and temporal trends of congenital heart disease in the middle-income country: a population-based study. Congenit Heart Dis. 2018;13(6):1012-27. doi: 10.1111/chd.12672.

19. Khoshnood B, Lelong N, Houyel L, Thieulin AC, Jouannic JM, Magnier $\mathrm{S}$, et al. Prevalence, timing of diagnosis and mortality of newborns with congenital heart defects: a population-based study. Heart. 2012;98(22):1667-73. doi: 10.1136/heartjnl-2012-302543.
20. Pfitzer C, Helm PC, Ferentzi H, Rosenthal LM, Bauer UMM, Berger F, et al. Changing prevalence of severe congenital heart disease: results from the National Register for Congenital Heart Defects in Germany. Congenit Heart Dis. 2017;12(6):787-93. doi: 10.1111/chd.12515.

21. Oster ME, Lee KA, Honein MA, Riehle-Colarusso T, Shin M, Correa A Temporal trends in survival among infants with critical congenital heart defects. Pediatrics. 2013;131(5):e1502-8. doi: 10.1542/peds.2012-3435.

22. Øyen N, Diaz LJ, Leirgul E, Boyd HA, Priest J, Mathiesen ER, et al Prepregnancy diabetes and offspring risk of congenital heart disease: a nationwide cohort study. Circulation. 2016;133(23):2243-53. doi: 10.1161/ CIRCULATIONAHA.115.017465

23. Siu SC, Sermer M, Colman JM, Alvarez AN, Mercier LA, Brian CM, et al. Clinical investigation and reports prospective multicenter study of pregnancy outcomes in women with heart disease. Circulation. 2001;104(5):515-21. doi: 10.1161/hc3001.093437.

24. Sun R, Liu M, Lu L, Zheng Y, Zhang P. Congenital heart disease: causes, diagnosis, symptoms, and treatments. Cell Biochem Biophys. 2015;72(3):857-60. doi: 10.1007/s12013-015-0551-6.

25. Mercuro G, Bassareo PP, Mariucci E, Deidda M, Zedda AM, Bonvicini M. Sex differences in congenital heart defects and genetically induced arrhythmias. J Cardiovasc Med. 2014;15(12):855-63. doi: 10.2459/ JCM.0b013e32835ec828.

26. Massin MM, Astadicko I, Dessy H. Noncardiac comorbidities of congenital heart disease in children. Acta Paediatr. 2007;96(5):753-5. doi: 10.1111/j.1651-2227.2007.00275.x

27. Krishnamurthy G, Ratner V, Bacha E, Aspelund G. Comorbid conditions in neonates with congenital heart disease. Pediatr Crit Care Med. 2016;17(8 Suppl 1):367-76. doi: 10.1097/PCC.0000000000000832.

28. Smith JMC, Andrade JG, Human D, Field TS. Adults with complex congenital heart disease: cerebrovascular considerations for the neurologist. Front Neurol. 2019;10:329.doi: 10.3389/fneur.2019.00329. 